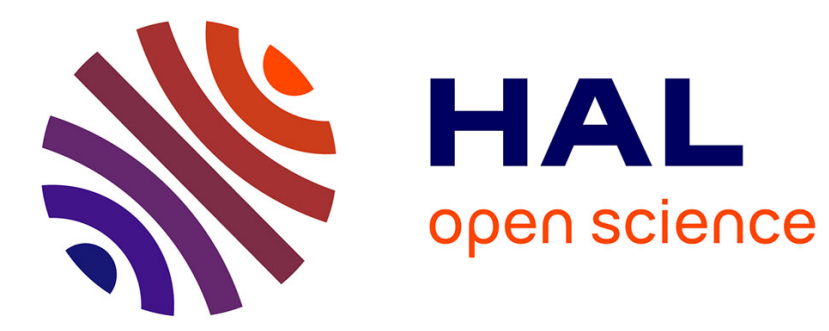

\title{
Nucleophilicity parameters for strong nucleophiles in dimethyl sulfoxide. A direct alternative to the $\mathrm{s}(\mathrm{E}+\mathrm{N})$ equation
}

T. William Bentley

\section{- To cite this version:}

T. William Bentley. Nucleophilicity parameters for strong nucleophiles in dimethyl sulfoxide. A direct alternative to the $\mathrm{s}(\mathrm{E}+\mathrm{N})$ equation. Journal of Physical Organic Chemistry, 2011, 24 (4), pp.282. 10.1002/poc.1747 . hal-00625939

\section{HAL Id: hal-00625939 \\ https://hal.science/hal-00625939}

Submitted on 23 Sep 2011

HAL is a multi-disciplinary open access archive for the deposit and dissemination of scientific research documents, whether they are published or not. The documents may come from teaching and research institutions in France or abroad, or from public or private research centers.
L'archive ouverte pluridisciplinaire HAL, est destinée au dépôt et à la diffusion de documents scientifiques de niveau recherche, publiés ou non, émanant des établissements d'enseignement et de recherche français ou étrangers, des laboratoires publics ou privés. 


\section{Journal of Physical Organic Chemistry}

WILEY

\section{Nucleophilicity parameters for strong nucleophiles in dimethyl sulfoxide. A direct alternative to the $s(E+N)$ equation}

\begin{tabular}{|r|l|}
\hline Journal: & Journal of Physical Organic Chemistry \\
\hline Manuscript ID: & POC-10-0063.R2 \\
\hline Wiley - Manuscript type: & Research Article \\
\hline $\begin{array}{r}\text { Date Submitted by the } \\
\text { Author: }\end{array}$ & 30-Apr-2010 \\
\hline Complete List of Authors: & Bentley, T.; UW Swansea, Chemistry \\
\hline Keywords: & $\begin{array}{l}\text { nucleophilicity scales, Swain-Scott equation, nucleophiles, } \\
\text { benzhydrylium cations, quinone methides }\end{array}$ \\
\hline \multicolumn{3}{c}{} \\
\multicolumn{3}{c}{$\begin{array}{c}\text { SCholarONE } \\
\text { Manuscript Central }\end{array}$} \\
\hline
\end{tabular}




\title{
Nucleophilicity parameters for strong nucleophiles in dimethyl
} sulfoxide. A direct alternative to the $s(E+N)$ equation

\author{
T. William Bentley*
}

\begin{abstract}
A scale of nucleophilicity $\left(N^{\prime \prime \prime}\right)$ for relatively strong nucleophiles (e.g. carbanions and amines), spanning over 5 orders of magnitude was constructed directly from experimental rate constants for reactions of 34 nucleophiles with a benzhydrylium cation, (lil) $)_{2} \mathrm{CH}^{+}\left(\log k=N^{\prime \prime \prime}\right.$ in dimethyl sulfoxide at $\left.20{ }^{\circ} \mathrm{C}\right)$. The equation $\log k=$ $\left(E^{\prime \prime \prime}+s_{E} N^{\prime \prime \prime}+c\right)$, where $E^{\prime \prime \prime}$ is an electrophilicity parameter, $s_{\mathrm{E}}$ is a Swain-Scott type of response parameter (to variation in nucleophilicity) for the electrophile, and $\mathrm{c}$ is a residuals term, is used to correlate second order rate constants for reactions of nucleophiles with other benzhydrylium cations, quinone methides (QM) and Michael-acceptor electrophiles. Contrary to published claims (Mayr et al. Angew Chem. Int. Edn. 2002, 41, 92, and later work), $s_{\mathrm{E}}$ increases as the reactivity of the QM decreases. The $N^{\prime \prime \prime}$ scale was extended a further 3 orders of magnitude by an extrapolation involving a QM electrophile. In contrast, published procedures involve over 40 reference electrophiles and over 100 adjustable parameters obtained from the equation $\log k=s_{N}(E+N)$, where $k$ is the rate constant, and $s_{N}$ is a nucleophile parameter. Values of $N-N^{\prime \prime \prime}$ in DMSO increase by 8 log units, as the reactivity of the nucleophile increases, because $N$ is a floating scale whereas $N^{\prime \prime \prime}$ is a fixed scale.
\end{abstract}




\author{
* Chemistry Unit, Grove Building, Swansea University, Singleton Park, Swansea SA2 \\ 8PP, Wales, UK \\ Email: t.w.bentley@swansea.ac.uk
}

KEYWORDS: nucleophilicity scales, Swain-Scott equation, nucleophiles, benzhydrylium cations, quinone methides

\title{
INTRODUCTION
}

The general equation (1) has recently been proposed to correlate logarithms of rate constants $(\log k)$ at $20{ }^{\circ} \mathrm{C}$ for a huge range of reactions of electrophiles (electrophilicity $E$ ) and nucleophiles (nucleophilicity $N$ ); in Eqn (1), $s_{\mathrm{N}}$ is referred to as a 'nucleophilespecific' parameter and $s_{\mathrm{E}}$ as an 'electrophile-specific' parameter. ${ }^{[1,2]}$ It is then assumed that $s_{\mathrm{E}}=1$ for many reactions, so 'deriving' Eqn (2) which had already been used in plots of $\log k v s . E$ to evaluate values of $s_{\mathrm{N}}$ (from slopes) and $N$ (from the intercept on the abscissa) for over 100 nucleophiles. ${ }^{[3,4]}$

Originally ${ }^{[1-4]}$ the symbol $s$ was chosen for Eqn (2), but it is not the same as the $s$ (or $s_{\mathrm{E}}$ ) parameter in the well established Swain-Scott equation (3). ${ }^{[5]}$ Consequently $s_{\mathrm{N}}$ is more appropriate than s for Eqn (2). Equation (4) fits many cation - anion recombinations, ${ }^{[6]}$ and the absence of an response parameter is consistent with the assumption $^{[1,2]}$ that $s_{\mathrm{E}}=1$. In Eqns (3) and (4), $n$ or $N_{+}$quantify nucleophilicity, and $k_{0}$ refers to a reference reaction, so relative rates are correlated. 


$$
\begin{aligned}
& \log k=s_{\mathrm{E}} s_{\mathrm{N}}(E+N) \\
& \log k=s_{\mathrm{N}}(E+N) \\
& \log k / k_{0}=s n \\
& \log k / k_{0}=N_{+}
\end{aligned}
$$

The question 'How constant are Ritchie's constant selectivity relationships' was the title of a recent paper, ${ }^{[7]}$ concluding that $s_{\mathrm{E}}$ is constant if anomalous data for water are excluded. Recognising this problem earlier, Ritchie proposed ${ }^{[6]}$ that the reference nucleophile (rate constant $k_{0}$ ) be hydroxide, instead of water which was chosen in earlier work $^{[8]}$ in line with Eqn (3). There are various $N_{+}$scales, ${ }^{[6]}$ and ideally the reference electrophile should be specified when $N_{+}$correlations are reported.

Published work ${ }^{[3,4]}$ on $N$ scales uses values of $E$ for a 'basis set' of 23 reference electrophiles; the electrophilicities of seven benzhydrylium cations, ranging in values of $E$ from 0 to 6 were defined by rate constants for reactions with 2 -methylpent-1-ene, ${ }^{[3]}$ and values of $E$ down to -10 (along with $N$ values for 38 nucleophiles) were then obtained by a multi-parameter extrapolation procedure (MPC1, Scheme 1). ${ }^{[3]}$ Plots of $\log k v s . E$ for individual nucleophiles then gave new values of $N$. This complex procedure (upper half of Scheme 1) leads to a floating scale when $s_{\mathrm{N}} \neq 1$, referring to dichloromethane (DCM) as solvent at $20{ }^{\circ} \mathrm{C}$ : (i) which deviates from a fixed scale by 5 orders of magnitude; (ii) in which none of the $>200$ parameters are defined by directly-determined experimental data. $^{[9]}$ 


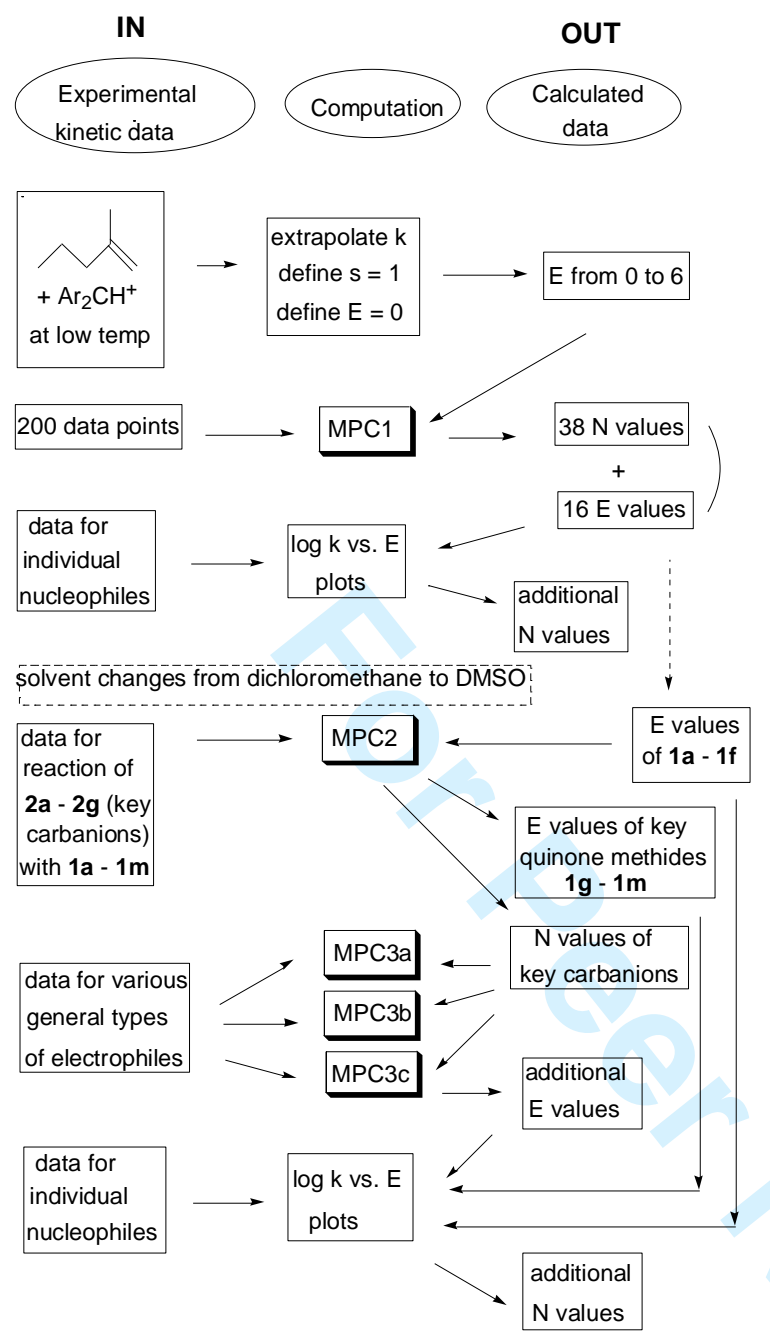

Scheme 1. An outline of the data processing by multi-parameter correlations (MPC) and $\log k$ vs. $E$ plots, previously employed to obtain $E$ and $N$ values from Eqn (2); MPC1 is in Reference [3] and MPC2 is based on References [11, 12]; there are 6 MPC3 correlations (3a, $3 b$ etc) in References [13-18]

An alternative design was reported recently; ${ }^{[9]}$ two benzhydrylium cations were chosen to define $N^{\prime}$ and $N^{\prime \prime}$ directly from experimental data (Eqns (5) and (6)), and the 
two fixed scales were linked by the formula $N^{\prime}-N^{\prime \prime}=6.6$. To avoid complications from solvent effects, ${ }^{[10]}$ only kinetic data in DCM were evaluated. ${ }^{[9]}$

$$
\begin{aligned}
& \log k=N^{\prime} \text { for decay of } \mathbf{1 n} \text {, at } 20{ }^{\circ} \mathrm{C} \\
& \log k=N^{\prime \prime} \text { for decay of } 1 \mathbf{a} \text {, at } 20{ }^{\circ} \mathrm{C}
\end{aligned}
$$

To further extend the $N$ scale to reactions of carbanions and other nucleophiles in dimethyl sulfoxide (DMSO), six cations $(\mathbf{1 a}-\mathbf{1 f})$ and seven quinone methides (QM, 1g1m) were chosen ${ }^{[11,12]}$ as reference electrophiles (the codes $\mathbf{1 a}-\mathbf{1 m}$ in Scheme 2 are the same as in the key paper $\left.{ }^{[11]}\right)$. Kinetic data for reactions of these electrophiles with key nucleophiles (Scheme 3) underwent another correlation (MPC2, Scheme 1), further extrapolating the $E$ scale from -10 to $-18 .^{[11]}$ The derived $N$ values were then the input for MPC3a, MPC3b etc, characterising $E$ values for other electrophiles from $E=-8$ to -23 . $^{[13-}$

${ }^{18]}$ Finally, $\log k$ vs. $E$ plots gave additional values of $N$ for stronger nucleophiles. ${ }^{[19-25]}$

Using Eqn (2) the slope defines $s_{\mathrm{N}}$ and intercept on the abscissa defines $N$, so residual errors are incorporated into the parameters, and when $s_{\mathrm{N}} \neq 1$ the $N$ scale 'floats' (the reference point is variable and hypothetical). Consequently, it is virtually impossible to define the parameters, and revision of one input rate constant in MPC1 would affect hundreds of other parameters. This procedure is indirect ( $N$ values are obtained from the $E$ scale) and requires long extrapolations, exacerbating errors inherent in a simple model.

A much simpler alternative design, avoiding a floating scale and requiring much shorter extrapolations, will now be presented using the same published kinetic data. ${ }^{[7,11-25]}$ The results will complete the alternative design, ${ }^{[9]}$ will lead to a $N^{\prime \prime \prime}$ scale in DMSO (fixed 
not floating), and will show (contrary to recent claims ${ }^{[1,2,7]}$ ) that the electrophile parameter $\left(s_{\mathrm{E}}\right)$ varies significantly. Selection of the mid-range electrophile (1a) as reference for a unified $N^{\prime \prime}$ scale (linked to $N^{\prime \prime \prime}$ and $N^{\prime}$ ) will also be discussed.

\section{RESULTS}

$N^{\prime}$ (Eqn (5)) refers to the reactions of the relatively reactive dianisyl cation (1n, Scheme 2), for which $E=0$, giving $N^{\prime}$ values for very weak nucleophiles (e.g. arenes). ${ }^{[9]}$ The less reactive dimethylaminobenzhydrylium cation (1a) gives $N^{\prime \prime}$ (Eqn (6)) for more reactive nucleophiles (e.g. enamines). ${ }^{[9]} N^{\prime \prime \prime}$ for even more reactive nucleophiles including carbanions will now be evaluated from cation (1f) using Eqn (7) and from additional Swain-Scott type correlations (Eqn (8)) for the auxiliary reference QM (1m).

$$
\begin{aligned}
& \log k=N^{\prime \prime \prime} \text { for decay of } \mathbf{1 f} \text { at } 20{ }^{\circ} \mathrm{C} \\
& \log k=E^{\prime \prime \prime}+s_{E} N^{\prime \prime \prime}+c
\end{aligned}
$$


$1 b$

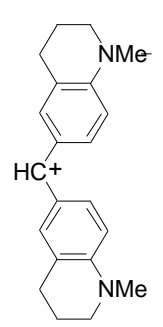

(thq) ${ }_{2} \mathrm{CH}^{+}$

$$
E=-8.22
$$

1c

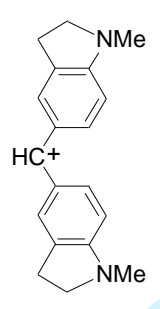

(ind) ${ }_{2} \mathrm{CH}^{+}$

$\mathrm{E}=-8.76$

1d

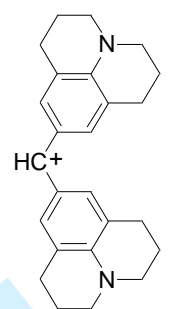

(jul $)_{2} \mathrm{CH}^{+}$

$E=-9.45$

$1 e$

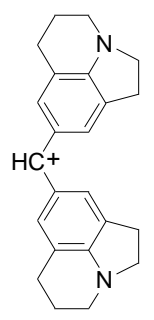

(lii) ${ }_{2} \mathrm{CH}^{+}$

$\mathrm{E}=-10.04$

$1 f$

reference substrate for $\mathrm{N}^{\prime \prime}$

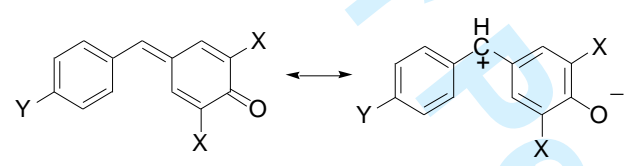

1g, $Y=O M e, X=B r, E=-8.63 \quad$ 1j, $Y=M e, X=B u^{t}, E=-15.83$

1h, $Y=O M e, X=P h, E=-12.18$ 1k, $Y=O M e, X=B u^{t}, E=-16.11$

1i, $Y=\mathrm{NMe}_{2}, X=\mathrm{Ph}, E=-13.39$ 1l, $Y=\mathrm{NMe}_{2}, X=\mathrm{Bu}^{\mathrm{t}}, \mathrm{E}=-17.29$
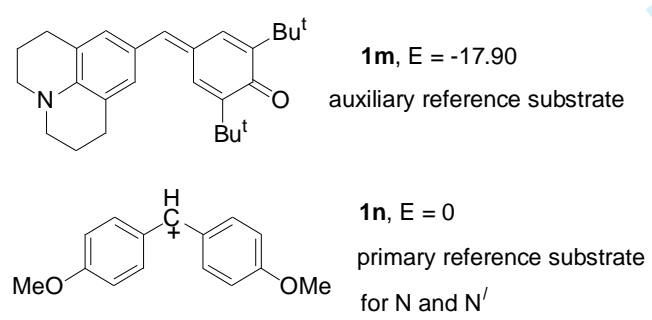

Scheme 2. Codes and electrophilicities for the 6 benzhydryl cations $(\mathbf{1 a}-\mathbf{1 f}$,) and 7

quinone methides (QM, $\mathbf{g} \mathbf{g} \mathbf{1 m})$, required for the multi-parameter correlation (MPC2) fit to Eqn (2): ${ }^{[11]} E=0$ for $\mathbf{1 n}$ 


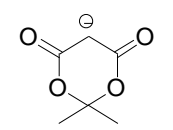

$2 a$

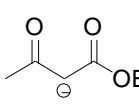

2d

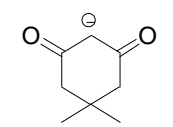

$2 \mathrm{~b}$

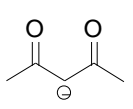

2c

Scheme 3. The 7 key carbanions $(\mathbf{2 a}-\mathbf{2 g})$ required for the multi-parameter correlations (MPC2, MPC3a, 3b etc, Scheme 1) for Eqn (2) $)^{[11,13-18]}$

The data including QMs $(\mathbf{1 g}-\mathbf{1 m})$ were processed $^{[11]}$ by MPC2, assuming the same $E$ values of cations $(\mathbf{1 a}-\mathbf{1 f})$ from previous work ${ }^{[1]}$ in DCM; 21 adjustable parameters $(E$ values of 7 quinone methides $(\mathrm{QM}, \mathbf{1 g}-\mathbf{1 m})$ and $s_{\mathrm{N}}$ and $N$ values for 7 enolates, $\mathbf{2 a} \mathbf{- 2} \mathbf{g}$, Scheme 3) were obtained from 70 data points, ${ }^{[11]}$ (additional rate constants for $\mathrm{MeCHNO}_{2}{ }^{-}$reacting with $\mathbf{1 k} \mathbf{1} \mathbf{l}$ and $\mathbf{1 m}$ were included in $\left.\mathrm{MPC} 2^{[11]}\right)$.

In contrast, values of $N^{\prime \prime \prime}($ Eqn (7)) can be obtained directly from experimental data ${ }^{[11,12]}$ considering Eqn (8) when $N^{\prime \prime \prime}=0, \log k=E^{\prime \prime \prime}+c=0$, so no adjustable parameters are required at this stage. Values of $N^{\prime \prime \prime}$ and $N\left(\right.$ Eqn (2)) show that $N-N^{\prime \prime \prime}$ increases as $N$ increases (Table 1), as expected for a floating $N$ scale. ${ }^{[9]}$ Values of $N^{\prime \prime \prime}$ for 27 additional nucleophiles (Scheme 4) were also calculated (Table 2) from data published later, ${ }^{[7,19-23]}$ giving a total of 34 values of $N^{\prime \prime \prime}$ from Eqn (7) in Tables 1 and 2. Correlations using Eqn (8, Tables 3 and 4) require 24 adjustable parameters (two per electrophile, excluding 1f), whereas Eqn $(2)$ requires many more $(13+(2 \times 34)=81)$. 
The data in Table 3 were obtained using Microsoft Excel, and show slopes, intercept, correlation coefficients (r) and number of data points (n). The slopes show that $s_{\mathrm{E}}$ is very close to unity, but the data vary from extensive $(\mathrm{n}=19)$ for $\mathbf{1 e}$, for which the correlation is very good, to less convincing for $\mathbf{1 a}$ and $\mathbf{1 b}$ because $\mathrm{n} \leq 5$ (also, despite their small number the range of nucleophiles is diverse (Table 3 footnotes $d$ and f)). Correlations using Eqn (8) for QMs (1g - 1m) reacting with carbanions (Table 4) include rate constants for $\mathbf{1 1}$ and $\mathbf{1 m}$ covering less than $2.5 \mathrm{log}$ units; the data show 'scatter' when the additional nucleophiles are included; the distribution of data points also increases uncertainties in the values of intercepts $\left(E^{\prime \prime \prime}+c\right)$, because extrapolations are required from typical values of $N^{\prime \prime \prime}(>3.0)$ to $N^{\prime \prime \prime}=0$. Another indication of the reliability of the correlations is the standard errors - the worst is small ( 0.27 for 11$)$. In contrast to the data in Table 3, the results show a substantial increase in $s_{E}$ (selectivity) as $E^{\prime \prime \prime}$ (reactivity) decreases. 
From the equation for $1 \mathbf{d}$ (Table 3$)$, it is predicted that $\log k_{\text {calc }}=2.22\left(\log k_{\mathrm{obs}}=\right.$ $2.02^{[21]}$ ) for reaction of $\mathbf{1 d}$ with the ylid $\mathrm{Ph}_{3} \mathrm{PCHCO}_{2} \mathrm{Et}$; however, reaction of the ylid with 1h is predicted to be slower than observed $\left(\log k_{\text {calc }}=-1.04, \log k_{\mathrm{obs}}=0.03^{[21]}\right)$.

Eqn (9), based on the first entry for $\mathbf{1 m}$ in Table 4, was then applied to estimate $N^{\prime \prime \prime}$ values for 10 more reactive nucleophiles by extrapolation (Table 5). Provisional data for 3 other nucleophiles are estimated from correlations for other QMs (1h. 1j and $\mathbf{1 k})$.

$N^{\prime \prime \prime}=(\log k($ for $1 \mathbf{m})-8.0) / 1.43$

Having obtained values of $N^{\prime \prime \prime}$ for 34 nucleophiles from the same reference nucleophiles and electrophiles as LLM (Schemes 2 and 3), ${ }^{[11]}$ correlations using Eqn (8) were carried out for 19 other electrophiles (Table 6); these all involve Michael additions to structurally-similar substrates $(\mathbf{1 0}-\mathbf{1 8})$, Scheme 5. Correlations for 5 additional QMs (Scheme 6) reacting with key carbanions (Scheme 3) are shown in Table 7.

Intercepts refer to $N^{\prime \prime \prime}=0$, and errors for neutral substrates (Tables 6 and 7) are relatively large because long extrapolations from $N^{\prime \prime \prime} \sim 5$ are often required. Calculated values agree better than expected from the errors in individual parameters: e.g. for Michael addition of 9 to $\mathbf{1 0}, \mathrm{Z}=\mathrm{OMe}$, the two entries (Table 6) for Eqn (8) predict $\log k$ $=6.03$ and 6.09, in agreement with the Eqn (2) prediction of 6.14; the experimental value is only 5.26, ${ }^{[24]}$ and as noted earlier ${ }^{[22,24]}$ Michael acceptors react more slowly than expected from parameters based on cations and QMs (e.g. see Table 6, footnotes $\mathrm{h}$ and $\mathrm{j}$ ).

Nucleophilicity parameters for amines (Table 2) can be used to predict rate constants for Michael additions (kinetic data for amines were not included in the 
correlations shown in Table 6). Predicted rate constants by either Eqn (2) or Eqn (8) for reactions of amines with $12, \mathrm{Z}=\mathrm{H}$ agree satisfactorily with experimental values. ${ }^{[14]}$ However, primary and secondary amines react with $\mathbf{1 6}$ about 100-fold faster than predicted, perhaps because of transition state stabilisation by H-bridges. ${ }^{[16]}$
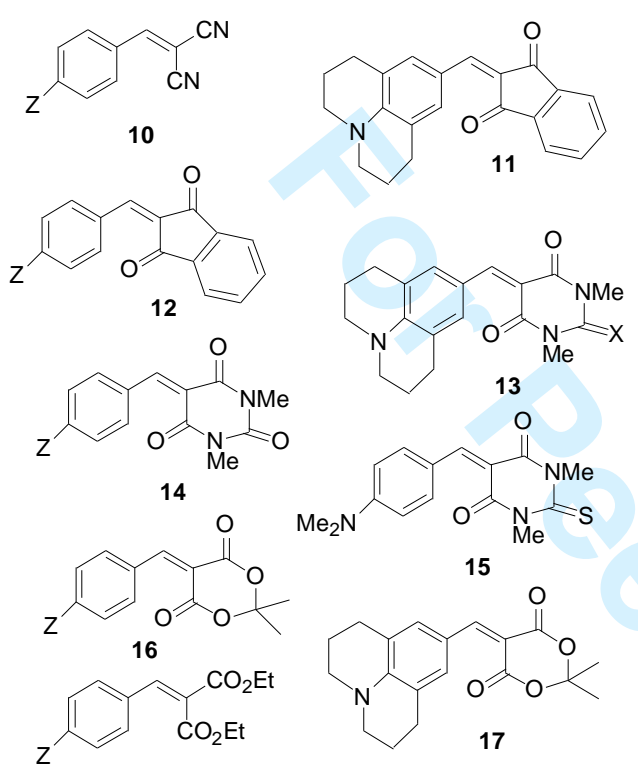

18

Scheme 5. Additional electrophiles for correlations shown in Table 6 


\section{DISCUSSION}

\section{Comparisons of $s_{E}$ with $\beta$ and of $N^{\prime \prime \prime}$ with $N$}

$N^{\prime \prime \prime}$ correlations (Eqn (8)) for over 300 rate constants in DMSO at $20{ }^{\circ} \mathrm{C}$ show good correlations for benzhydrylium ions (Table 3) and QMs (Tables 4 and 7), but are less satisfactory for Michael additions (Table 6). As for other cations, ${ }^{[6,8]}$ the parameter $s_{\mathrm{E}}$ is approximately constant $\left(s_{\mathrm{E}}=1.00\right.$, Table 3$)$, but $s_{\mathrm{E}}$ varies between 1.0 and 1.5 for QMs (Tables 4 and 7). Nucleophilic attack on activated 9-methylenefluorenes is known to give slopes $>1$ in plots $v s . N_{+},{ }^{[26]}$ and the tri- $p$-anisylmethyl cation has a lower response to changes in $N_{+}$than less reactive cations (crystal violet or malachite green). ${ }^{[27]}$

In general $s_{\mathrm{E}} \neq 1.00,{ }^{[28]}$ so Eqn (4) is a special case, and a selectivity parameter should be incorporated into the Ritchie Eqn (4). ${ }^{[26,27,29,30]}$ Consequently, it is not appropriate to 'derive' Eqn (2) by setting $s_{\mathrm{E}}=1.00$ in Eqn $(1),{ }^{[1,2]}$ and to then apply Eqn (1) to other electrophiles. ${ }^{[11,12]}$

Despite the questionable derivation, Eqn (2) is a useful way to predict structural effects on reactivity using the $E$ scale of electrophilicity and the substituent effect parameter $\left(s_{\mathrm{N}}\right)$, assuming that the 'electrophile specific' parameter $s_{\mathrm{E}}=1.00 .^{[1-4,7,11-25]}$ The alternative assumption that $s_{\mathrm{N}}=1.00$ leads to a variation on the Swain-Scott equation (Eqn (8)) and gives more reliable values for nucleophilicity parameters. ${ }^{[9,10]}$ The two approaches are different ways to locate a point in $3 \mathrm{D}$ space, and $s_{\mathrm{E}}$ and $s_{\mathrm{N}}$ are interdependent parameters. $^{[9,10]}$

$N^{\prime \prime \prime}$ correlates satisfactorily with $\mathrm{p} K_{\mathrm{a}}$ for 27 nucleophiles in DMSO (Figure 1). Two correlation lines are shown: six cyano- stabilised carbanions, including arylacetonitriles 
$(\mathbf{7}, \mathbf{8})$ but also $2 \mathbf{e}$ and $\mathbf{2 f}$, fit one line; nine sulfonyl-stabilised carbanions $(\mathbf{3}, \mathbf{5})$, and four enolates (2a, 2b, 2c and $\mathbf{2 g}$ ) fit a parallel line (such family behaviour is typical ${ }^{[35]}$ ). The remaining eight nucleophiles (all nitro-stabilised) are close to the two correlation lines, but show distinct curvature possibly due to the failure of $\mathrm{p} K_{\mathrm{a}}$ to model the kinetic phenomena of desolvation. ${ }^{[35]}$

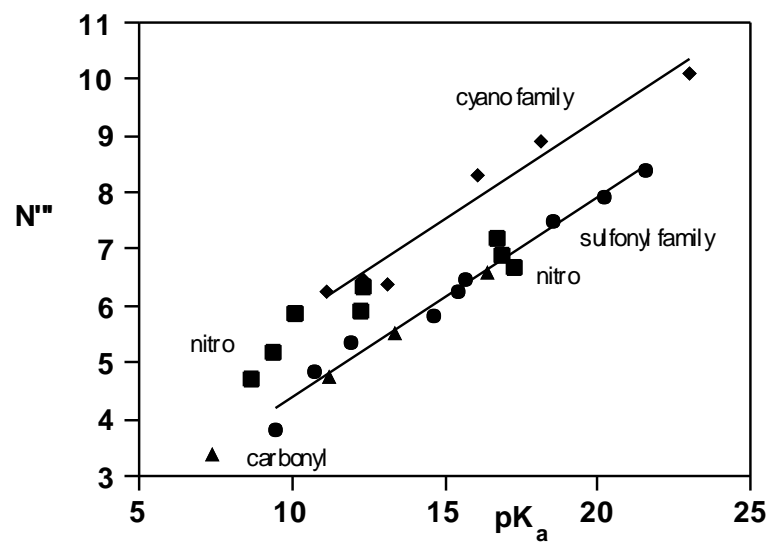

Figure 1. Brønsted plot $\left(N^{\prime \prime \prime}\right.$ at $20^{\circ} \mathrm{C} v s . \mathrm{p} K_{\mathrm{a}}$ at $\left.25^{\circ} \mathrm{C}\right)$ for 27 carbanions in DMSO. $N^{\prime \prime \prime}$ from Tables 1, 2 and 5, and $\mathrm{p} K_{\mathrm{a}}$ data from References [31-34]; separate correlation lines with $\beta=0.35 \pm 0.04(\mathrm{r}=0.978)$ are shown for six cyano-stabilised carbanions $(\mathbf{2 e}, \mathbf{2} \mathbf{f}, \mathbf{7}$ and 8), and with $\beta=0.35 \pm 0.02(\mathrm{r}=0.991)$ for nine sulfonyl-stabilised carbanions $(\mathbf{3}, \mathbf{5})$

The value of $\beta=0.35 \pm 0.04$ (Figure 1) for reactions of $\mathbf{1 f}$ with nucleophiles, is the same within errors or slightly lower than the value of $\beta=0.40^{[33]}$ for reactions of $n$-butyl chloride reacting with benzyl phenylsulfonyl carbanions. Both $\beta$ and $s_{\mathrm{E}}$ show the effect of varying the nucleophile for a fixed electrophile, so an $\mathrm{S}_{\mathrm{N}} 2$ reaction is responding more than a cation-anion recombination. A correlation of $N_{+}($Eqn (4)) with $n$ (Eqn (3)) in 
water has a slope of $2.0^{[36]}$ or $2.1 .^{[37]}$ So, in contrast to the results in DMSO, cation-anion recombinations $\left(N_{+}\right)$in water are twice as sensitive as $S_{N} 2$ reactions $(n)$ to variations in nucleophilicity.

For nucleophilic additions to the QM (11) in DMSO, $\beta=0.58^{[22]}$ (or $\sim s_{\mathrm{E}} \times 0.35=$ 0.50), again illustrating that $s_{\mathrm{E}}>1$ for QMs $(\mathbf{1}, \mathbf{1 9})$. QM $(\mathbf{2 0})$ may be treated as a strongly resonance-stabilised carbocation ${ }^{[36]}$ for nucleophilic additions to 20 in water, an $N_{+}$ correlation has slope $\left(s_{\mathrm{E}}\right)$ of only $0.92,{ }^{[36]}$ fitting the trend that more reactive QMs have lower values of $s_{\mathrm{E}}$ (Tables 3 and7).

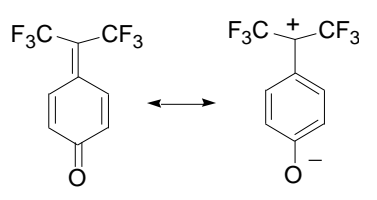

20

When $N^{\prime \prime \prime}$ is defined directly by Eqn (7), values of $\Delta N=N-N^{\prime \prime \prime}$ for the key carbanions (Table 1) vary by $3.1 \log$ units, whereas the total range of values of $N^{\prime \prime \prime}$ is only 3.2; the additional nucleophiles in Table 2 also show substantial variations in $\Delta N$ (Table 2). When the extrapolated data for more reactive carbanions is included, values of $\Delta N$ range from 10.5 (Table 1) or 10.8 (Table 2) to 18.9 (Table 5). The floating $N$ scale varies from 12.15 (Table 2) to 28.95 (Table 5), and all of the correlations (MPC2, 2, 3a 3b, 3c etc, Scheme 1) are needed. For the same range of nucleophiles, the fixed $N^{\prime \prime \prime}$ scale varies only from 1.35 (Table 2) to 10.1 (Table 5). The above calculations indicate that during the complex sequences of processing of the kinetic data (Scheme 1), the $N$ scale floats by 8 orders of magnitude away from the initial reference point (1n). 
It was mentioned over a decade ago that $N$ is a floating scale,${ }^{[38]}$ but the large extent of floating has only recently been highlighted. ${ }^{[9]}$ Theoretically, it should be possible to correct from the floating $N$ scale to a fixed scale $s_{\mathrm{N}} N$. However, this requires a high level of confidence in a long extrapolation of complex substituent effects, ${ }^{[39,40]}$ and neglect of solvent effects. In practice, $s_{\mathrm{N}} N$ does not give a satisfactory trend with $\mathrm{p} K_{\mathrm{a}}$ for arylacetonitriles (Table 8), and, these carbanions also deviate from a plot of $N v s . \mathrm{p} K_{\mathrm{a} .}{ }^{[23]}$ in contrast to $N^{\prime \prime \prime}$ (Figure 1).

\section{Constant selectivity plots and electrophilicity parameters}

The chosen methodology ${ }^{[9,10]}$ (Case 1: fix $E$, vary $N$, extrapolate to estimate $E$ ) is designed to lead to a reliable scale of nucleophilicity, with most of the errors incorporated into the extrapolated values of $E^{\prime \prime \prime}+c$. In contrast, published procedures (Case 2: fix $N$, vary $E$, extrapolate to obtain $N^{[3,7,19-25]}$ ) lead to less reliable values of $N$, which include most of the errors. Both cases are based on the assumptions that $\log k$ depends on parameters for electrophilicity and nucleophilicity. Consequently, published values of $E$ should be closely related to the extrapolated values of $E^{\prime \prime \prime}+c$, as observed (Figure 2).

The slopes of the correlation lines for reactions of the key carbanions with benzhydrylium ions (Table 3) and QMs (Table 4) are both 1.00 within calculated errors (Figure 2), but there is a separation between the two lines corresponding to 0.5 units on the X-axis. These results, coupled with the variations in $s_{\mathrm{E}}$ for QMs (Table 4), are unexpected. Therefore the constant selectivity plots, which are the foundations of Eqn (2), ${ }^{[41]}$ were reinvestigated. The constant selectivity plots for $\mathrm{QMs}^{[12]}$ are based on data for only 4 QMs $(\mathbf{1 j}-\mathbf{1 m})$, and slopes (based on limited data) vary from 0.81 for $\mathbf{2 a}$ to 
1.12 for $\mathbf{2 c}$ and $\mathbf{2 d}$, relative to $\log k$ for $\mathbf{2 f}$ as the model nucleophile for an $E$ scale. These results were shown ${ }^{[12]}$ in a graph omitting numerical values of the slopes, and the interpretation was made that the correlation lines are 'parallel'. ${ }^{[12]}$

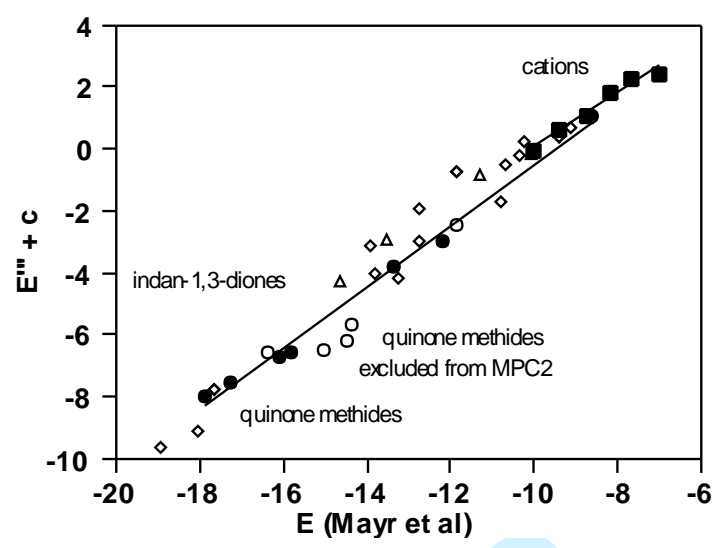

Figure 2. Plots of $E$ (Scheme 2) vs. $E^{\prime \prime \prime}+c$ for benzhydrylium cations (1a-1f, Table 3) and quinone methides (1g -1m, Table 4); the slopes of the correlation lines are $0.996 \pm$ $0.050(\mathrm{n}=6$,excluding 1a, $\mathrm{r}=0.996)$ and $0.984 \pm 0.034(\mathrm{n}=6, \mathrm{r}=0.997)$ respectively; data from Tables 6 and 7 are plotted for comparison (not fitted to correlation lines)

Combining two sources of experimental data ${ }^{[11,12]}$ leads directly (without 'optimisation') to an $E$ scale spanning 7 orders of magnitude in which QMs are for the first time included on the same selectivity plots as benzhydrylium ions. The ' $E$ scale' (Figure 3) is defined by $\log k$ for $\mathbf{2 b}$, the only nucleophile for which kinetic data for all cations and QMs $(\mathbf{1 a}-\mathbf{1 m})$ are available.

The slopes of correlation lines vary from 0.96 to 1.13 (Figure 3), are dominated by QMs, and cations show deviations (e.g. for 2g). Despite the idea that QMs are activated 
benzhydrylium ions, ${ }^{[11,12,36]}$ there is not a seamless connection between these reference electrophiles (see also Figure 2). MPC $2^{[11]}$ is able to adjust $E$ to enforce a fit to Eqn (2), but this procedure does not give confidence in extrapolations needed to obtain $N$.

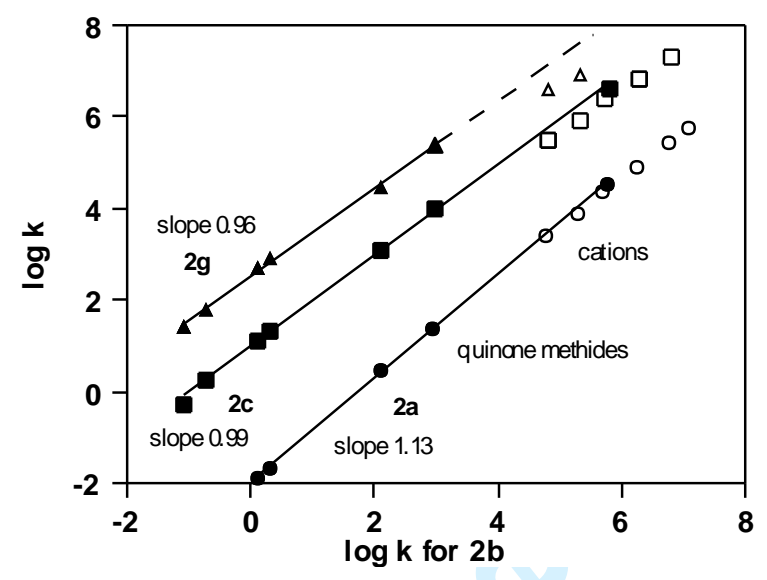

Figure 3. $\log k$ for reactions of $\mathbf{2 a}, \mathbf{2} \mathbf{c}$ and $\mathbf{2 g} v s$. corresponding data for $\mathbf{2 b}$, reacting with cations (open symbols) and quinone methides (QMs, filled symbols) in DMSO at 20 ${ }^{\circ} \mathrm{C}$; slopes (errors: $\pm 0.02, \mathrm{r}=0.999$ ) refer only to QMs; data from References $[11,12]$

Sufficient data are available to permit the calculation of $s_{\mathrm{N}}$ and $N$ for 4 key nucleophiles (2a -2d) from standard plots ${ }^{[3,7,19-25]}$ of $\log k v s . E$ for benzhydrylium ions; values of $N$ require a long extrapolation, and are significantly different (Table 9) from those obtained by MPC2 which includes data for QMs. Because of a leverage effect, $s_{\mathrm{N}}$ is determined mainly by QMs, not benzhydrylium cations, and the differences in slopes (Figure 3 and $s_{\mathrm{N}}$, Table 9) show that $s_{\mathrm{N}}$ is not exactly 'nucleophile specific'. Also, unlike Eqn (8) which utilises a different equation to calculate parameters, the differences in Table 9 are due solely to the exclusion of QMs from the data processing to fit Eqn (2). 


\section{Towards a unified $\mathrm{N}^{\prime \prime}$ scale of nucleophilicity}

As expected from $N_{+}$correlations, ${ }^{[6,8]}$ slopes (Table 3 ) are close to unity for reactions of cations $(\mathbf{1 a}-\mathbf{1 f})$ with nucleophiles, and this allows connections to be made between the $N^{\prime}, N^{\prime \prime}$ and $N^{\prime \prime \prime}$ scales (Eqns (5 - 7)). Data for five nucleophiles (Table 3, footnote f) are available in DMSO for both 1a and 1f, giving $N^{\prime \prime}-N^{\prime \prime \prime}=2.2 \pm 0.2$ in DMSO. However, the scope of a unified scale for addition of nucleophiles to cations in DMSO is limited by the relatively high nucleophilicity of DMSO $\left(N=9.75\right.$ in acetonitrile $\left.{ }^{[25]}\right)$, so by this measure DMSO is more nucleophilic than water or typical alcohols, but less nucleophilic than amines (Table 2). Therefore, changes of solvent and consideration of solvent effects on rates is also required.

Cation-anion recombinations are the reverse of $S_{N} 1$ reactions, and solvent effects are likely to be significant, particularly for protic solvents. ${ }^{[9,42]}$ Considering only data for aprotic solvents, 22 values of $N^{\prime \prime}-N^{\prime \prime \prime}$ are available in DCM, giving $N^{\prime \prime}-N^{\prime \prime \prime}=2.4 \pm 0.4$, a slightly greater ratio than in DMSO. Reactions of the ylid $\mathrm{Ph}_{3} \mathrm{PCHCO}_{2} \mathrm{Et},{ }^{[43]}$ are faster in DCM than in DMSO, and the kinetic effect is larger for 1a, $N^{\prime \prime}\left(14\right.$-fold) than 1f, $N^{\prime \prime \prime}(5-$ fold); reaction of $\mathrm{PPh}_{3}$ with $\mathbf{1 a}$ is also faster (4-fold) in DCM than in DMSO. ${ }^{[4]}$

Carbanion 3, $\mathrm{Z}=\mathrm{NO}_{2}$ reacts about 10-fold faster in acetonitrile than DMSO, so presumably reactions in DCM will also faster. ${ }^{[20]}$

In contrast, other reactions are favoured by solvents with a higher donor number (e.g. ethyl diazoacetate reacting with $\mathbf{1 a}^{[45]}$ ); also reactions of amines are faster in DMSO than in acetonitrile (e.g. only 1.4 fold for piperidine and 1f, but 22-fold for $\mathrm{CF}_{3} \mathrm{CH}_{2} \mathrm{NH}_{2}$ and 1a), ${ }^{[7,18]}$ so presumably reactions in DCM will be slower than in DMSO. 
It appears that corrections for solvent effects in aprotic media will be relatively small, but not insignificant. No other generalisations will be attempted at this stage, because it is not easy to predict even whether rates will increase or decrease. If as a first approximation solvent effects are ignored (as proposed earlier ${ }^{[3]}$ ), connections (Scheme 7) can be made from $N^{\prime \prime}$ to $N^{\prime \prime \prime}$ and to $N^{\prime[9]}(=N$, when the $N$ scale is correctly attached to the fixed reference point $\mathbf{1 n}$ in DCM).

A unified, scale $\left(N^{\prime \prime}\right)$ is suggested, based on the less reactive electrophile (1a) in DCM at $20{ }^{\circ} \mathrm{C}$ as the fixed reference. ${ }^{[9]}$ The $N^{\prime \prime}$ scale spans over 22 orders of magnitude from 12.3 for $\mathbf{8}, \mathrm{Z}=\mathrm{H}\left(N^{\prime \prime \prime}=10.1\right.$, Table 5$)$ to -10.1 for $m$-xylene $\left(N^{\prime}=-3.5^{[9]}\right)$, so $\mathbf{1 a}$ is located centrally; ${ }^{[46]}$ the corresponding $N$ values are $28.9^{[23]}$ and $-3.54^{[3]}$ respectively, ranging over 32 orders of magnitude. Consequently, the $N$ scale floats by over 10 orders of magnitude relative to the fixed $N^{\prime \prime}$ scale!!

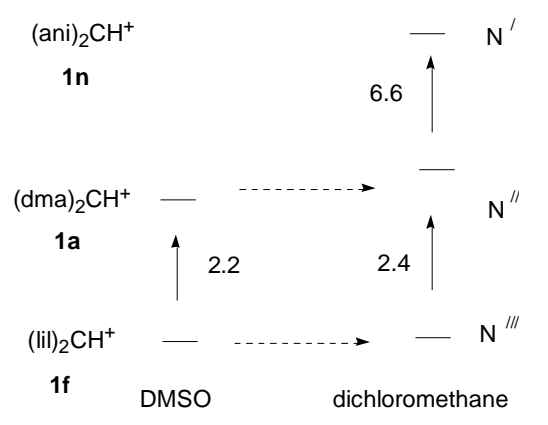

Scheme 7. Interconversion factors (increments of $\log k$ ) for $N^{\prime \prime \prime}$ in DMSO (this work) with $N^{\prime}$ or $N^{\prime \prime}$ in dichloromethane ${ }^{[9]}$

In general, it is not necessary to use a floating scale such as Eqn (2) to design a reactivity scale spanning 20 orders of magnitude. Three reference substrates (e.g. 1a, 1f, 
1n) are sufficient; e.g. a unified data set for bridgehead reactivity spanning $10^{23}$ in first order rate constants was established for tosylates, linked to triflates for less reactive substrates and to halides for more reactive substrates. ${ }^{[47]}$ Second order rate constants have the advantage that they can be obtained from pseudo-first order rate constants, and reactivities can be controlled by varying the concentrations of nucleophiles.

Simple additivity rules ${ }^{[48]}$ for estimating orders of magnitude of rates of reactions of electrophiles with nucleophiles can be devised using Scheme 7: e.g. Eqn (10), based on the $N^{\prime \prime \prime}$ scale and the established $E$ scale. ${ }^{[3,11]}$ Values of $\left(N^{\prime \prime \prime}+9\right)$ for 7 and 8 are $2-4$ orders of magnitude larger than $s_{\mathrm{N}} N$ (Table 8), the hypothetical values of $\log k$ when $E=$ 0.

$$
\log k \sim E+N^{\prime \prime \prime}+9
$$

\section{CONCLUSIONS}

Up to 8 multi-parameter correlations, ${ }^{[3,11,13-18]} 3$ of which are consecutive (Scheme 1 ), are required to extend the $E$ scale of electrophilicity from a well defined region between $E=6$ and $E=0$, all the way back to $E=-23.8 .^{[17]}$ Subsequent calculations of $N$ for strong nucleophiles give values which deviate from a fixed scale $\left(N^{\prime \prime \prime}\right.$, Eqn (8)) by up to $8 \log$ units (see values of $\Delta N=N-N^{\prime \prime \prime}$ in Tables 1.2 and 5), an extent of floating amounting to half of the whole range of $N$ values in DMSO. In contrast, the $N^{\prime \prime \prime}$ scale based on directly-defined values (Eqn (8)), can be extended by a much shorter extrapolation (Eqn (9)). Good $N^{\prime \prime \prime}$ correlations using Eqn (8) are observed for cations 
(Table 3) and quinone methides (Tables 4 and 7), but precision is lower for Michael additions (Table 6). $N^{\prime \prime \prime}$ also gives a satisfactory Brønsted plot (Figure 1).

Future work based on Eqns (6 - 8), with greater emphasis on $s_{\mathrm{E}},{ }^{[27-29]}$ should reveal solvent effects on electrophilicity for strong electron pair donor solvents such as water and alcohols. Currently, ${ }^{[3,11]} s_{\mathrm{E}}=1.00$ is assumed incorrectly (Table 4), and solvent effects on electrophilicity are ignored. 


\section{REFERENCES}

[1] T. B. Phan, M. Breugst, H. Mayr, Angew. Chem. Int. Ed. 2006, 45, 3869-3874.

[2] H. Mayr, A. R. Ofial, J. Phys. Org. Chem. 2008, 21, 584-595.

[3] H. Mayr, T. Bug, M. F. Gotta, N. Hering, B. Irrgang, B. Janker, B. Kempf, R. Loos,

A. R. Ofial, G. Remennikov, H. Schimmel, J. Am. Chem. Soc. 2001, 123, 9500-9512.

[4] H. Mayr, B. Kempf, A. R. Ofial, Acc. Chem. Res. 2003, 36, 66-77.

[5] C. G. Swain, C. B. Scott, J. Am. Chem. Soc. 1953, 75, 141-147.

[6] C. D. Ritchie, Can. J. Chem. 1986, 64, 2239-2250.

[7] S. Minegishi, H. Mayr, J. Am. Chem. Soc. 2003, 125, 286-295.

[8] C. D. Ritchie, Acc. Chem. Res. 1972, 5, 348-354.

[9] T. W. Bentley. J. Phys. Org. Chem. 2010, DOI 10.1002/poc.1670.

[10] T. W. Bentley, J. Phys. Org. Chem. 2010, 23, 30-36.

[11] R. Lucius, R. Loos, H. Mayr, Angew. Chem. Int. Ed. 2002, 41, 92-95.

[12] R. Lucius, H. Mayr, Angew. Chem. Int. Ed. 2000, 39, 1995-1997.

[13] T. Lemek, H. Mayr, J. Org. Chem. 2003, 68, 6880-6886.

[14] S. T. A. Berger, F. H. Seeliger, F. Hofbauer, H. Mayr, Org. Biomol. Chem. 2007, 5, 3020-3026.

[15] F. Seeliger, S. T. A. Berger, G. Y. Remennikov, K. Polborn, H. Mayr, J. Org. Chem. 2007, 72, 9170-9180.

[16] O. Kaumanns, H. Mayr, J. Org. Chem. 2008, 73, 2737-2745.

[17] O. Kaumanns, R. Lucius, H. Mayr, Chem. Eur. J. 2008, 14, 9675-9682.

[18] D. Richter, N. Hampel, T. Singer, A. R. Ofial, H. Mayr, Eur. J. Org. Chem. 2009, 3203-3211.

[19] T. Bug, T. Lemek, H. Mayr, J. Org. Chem. 2004, 69, 7565-7676.

[20] S. T. A. Berger, A. R. Ofial, H. Mayr, J. Am. Chem. Soc. 2007, 129, 9753-9761.

[21] R. Appel, R. Loos, H. Mayr, J. Am. Chem. Soc. 2009, 131, 704-714.

[22] F. Seeliger, H. Mayr, Org. Biomol. Chem. 2008, 6, 3052-3058.

[23] O. Kaumanns, R. Appel, T. Lemek, F. Seeliger, H. Mayr, J. Org. Chem. 2009, 74, 75-81. 
[24] S. T. A. Berger, T. Lemek. H. Mayr, Arkivoc. 2008(x), 37-53.

[25] T. B. Phan, C. Nolte, S. Kobayashi, A. R. Ofial, H. Mayr, J. Am. Chem. Soc. 2009, $131,11392-11401$.

[26] S. Hoz, D. Speizman, J. Org. Chem. 1983, 48, 2904-2910.

[27] K. Hillier, J. M. W. Scott, D. J. Barnes, F. J. P. Steele, Can. J. Chem. 1976, 54, 33123314.

[28] P. Denton, C. D. Johnson, J. Chem. Soc., Perkin Trans. 2, 1995, 477-481.

[29] S. Hoz, Acc. Chem. Res. 1993, 26, 69-74.

[30] J. P. Richard, T. L. Amyes, T. Vontor, J. Am. Chem. Soc. 1992, 114, 5626-5634.

[31] F. G. Bordwell, M. J. Bausch, J. Am. Chem. Soc. 1986, 108, 1979-1985.

[32] F. G. Bordwell, J.-P. Cheng, M. J. Bausch, J. E. Bares, J. Phys. Org. Chem. 1988, 1, 209-223.

[33] F. G. Bordwell, J. C. Branca, T. A. Cripe, Isr. J. Chem. 1985, 26, 357-366.

[34] Supplementary information, page S33 of Reference [20].

[35] F. G. Bordwell, T. A. Cripe, D. L. Hughes, Adv. Chem, Series, 1987, 215, 137-153.

[36] J. P. Richard, M. M. Toteva, J. Crugeiras, J. Am. Chem. Soc. 2000, 122, 1664-1674.

[37] J. W. Bunting, J. M. Mason, C. K. M. Heo, J. Chem. Soc., Perkin Trans. 2, 1994, 2291-2300.

[38] H. Mayr, O. Kuhn, M. F. Gotta, M. Patz, J. Phys. Org. Chem. 1998, 11, 642-654.

[39] I. Lee, Adv. Phys. Org. Chem. 1992, 27, 57 -117.

[40] Y. Tsuno, M. Fujio, Adv. Phys. Org. Chem. 1999, 32, 267-385.

[41] H. Mayr, M. Patz, Angew. Chem. Int. Ed. 1994, 33, 938-957.

[42] D. N. Kevill, M. J. D’Souza, J. Chem. Res. 2008, 61-66.

[43] R. Appel, R. Loos, H. Mayr, J. Am. Chem. Soc. 2009, 131, 704-714.

[44] H. Mayr, B. Kempf, Chem. Eur. J. 2005, 11, 917-927.

[45] T. Bug, M. Hartnagel, C. Schlierf, H. Mayr, Chem. Eur. J. 2003, 9, 4068-4076.

[46] T. W. Bentley, M. S. Garley, J. Phys. Org. Chem. 2006, 19, 341-349.

[47] T. W. Bentley, K. Roberts, J. Org. Chem. 1985, 50, 5852-5856.

[48] T. W. Bentley, Chem. Eur. J. 2006, 12, 6514-6520. 
Table 1. Comparisons of $N$ and $N^{\prime \prime \prime}$ for seven key carbanion nucleophiles in DMSO at 20 ${ }^{\circ} \mathrm{C}^{\mathrm{a}}$

Nucleophile $^{\mathrm{b}} \quad N^{\mathrm{c}} \quad N^{\prime \prime \prime} \mathrm{d} \quad \Delta N^{\mathrm{e}}$

$\begin{array}{lll}13.91 & 3.41 & 10.50\end{array}$

2b $16.27 \quad 4.78 \quad 11.49$

$\begin{array}{llll}-\mathrm{CH}(\mathrm{COMe})_{2}(\mathbf{2 c}) \quad 17.64 & 5.52 & 12.12\end{array}$

$\begin{array}{lll}18.82 & 6.08 & 12.74\end{array}$

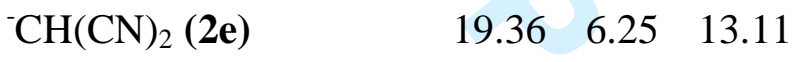

$\begin{array}{llll}\text { 2f } & 19.62 & 6.38 & 13.24\end{array}$

$\begin{array}{llll}-\mathrm{CH}\left(\mathrm{CO}_{2} \mathrm{Et}\right)_{2}(\mathbf{2 g}) & 20.22 & 6.61 & 13.61\end{array}$

${ }^{a}$ Kinetic data from References $[11,12]$.

${ }^{\mathrm{b}}$ See Scheme 3.

${ }^{c}$ From Eqn (2) and Reference [11].

${ }^{\mathrm{d}}$ From Eqn (7), this work.

${ }^{\mathrm{e}} \Delta N=N-N^{\prime \prime \prime}$. 
Table 2. Comparisons of $N$ and $N^{\prime \prime \prime}$ (Eqn (7)) for additional nucleophiles in DMSO at 20 ${ }^{\circ} \mathrm{C}$

Nucleophile

$N^{\mathrm{a}} \quad N^{\prime \prime \prime} \mathrm{b} \Delta N^{\mathrm{c}}$

$\mathrm{CF}_{3} \mathrm{CH}_{2} \mathrm{NH}_{2}{ }^{\mathrm{d}}$

$\begin{array}{lll}12.15 & 1.35 & 10.80\end{array}$

ylid $\mathrm{Ph}_{3} \mathrm{PCHCO}_{2} \mathrm{Et}^{\mathrm{e}}$

$\begin{array}{lll}12.21 & 1.40 & 10.81\end{array}$

$\mathrm{H}_{2} \mathrm{NCH}_{2} \mathrm{CO}_{2} \mathrm{Et}^{\mathrm{d}}$

$\begin{array}{lll}14.30 & 2.89 & 11.41\end{array}$

$\operatorname{EtCH}\left(\mathrm{NH}_{2}\right) \mathrm{CH}_{2} \mathrm{OH}^{\mathrm{f}}$

$\begin{array}{lll}14.39 & 2.92 & 11.47\end{array}$

$\mathrm{PhCH}_{2} \mathrm{NH}_{2}{ }^{\mathrm{f}}$

$15.28 \quad 3.40 \quad 11.88$

$\mathrm{MeCH}(\mathrm{OH}) \mathrm{CH}_{2} \mathrm{NH}_{2}{ }^{\mathrm{f}}$

$15.47 \quad 3.52 \quad 11.95$

$\operatorname{Pr}^{n} \mathrm{NH}_{2}{ }^{\mathrm{d}}$

$\begin{array}{lll}15.70 & 3.59 & 12.11\end{array}$

$\mathrm{NH}_{2} \mathrm{CH}_{2} \mathrm{CH}_{2} \mathrm{OH}^{\mathrm{f}}$

$\begin{array}{lll}16.07 \quad 3.67 & 12.40\end{array}$

$\left(\mathrm{HOCH}_{2} \mathrm{CH}_{2}\right)_{2} \mathrm{NH}^{\mathrm{f}}$

$\begin{array}{lll}15.51 & 3.79 & 11.72\end{array}$

3, $\mathrm{Z}=\mathrm{NO}_{2}{ }^{\mathrm{g}}$

$14.49 \quad 3.83 \quad 10.66$

morpholine ${ }^{\mathrm{d}}$

$16.96 \quad 4.66 \quad 12.30$

4, $\mathrm{Z}=4-\mathrm{NO}_{2}{ }^{\mathrm{h}}$

$16.29 \quad 4.71 \quad 11.58$

3, $\mathrm{Z}=\mathrm{CN}^{\mathrm{g}}$

$\begin{array}{lll}16.28 & 4.83 & 11.45\end{array}$

piperidine $^{\mathrm{d}}$

$17.19 \quad 5.05 \quad 12.14$

$4, \mathrm{Z}=4-\mathrm{CN}^{\mathrm{h}}$

$16.96 \quad 5.21 \quad 11.75$

3, $\mathrm{Z}=\mathrm{CF}_{3}^{\mathrm{g}}$

$\begin{array}{lll}17.33 & 5.37 & 11.96\end{array}$

$(\mathrm{EtO})_{2} \mathrm{P}(\mathrm{O}) \mathrm{CH}^{-} \mathrm{CN}^{\mathrm{e}}$

$\begin{array}{lll}18.57 & 5.56 & 13.01\end{array}$

$(\mathrm{EtO})_{2} \mathrm{P}(\mathrm{O}) \mathrm{CHC}\left(\mathrm{O}^{-}\right) \mathrm{OEt}^{\mathrm{e}}$

$19.23 \quad 5.76 \quad 13.47$ 

3, $\mathrm{Z}=\mathrm{H}^{\mathrm{g}}$
$\begin{array}{lll}18.67 \quad 5.81 & 12.86\end{array}$
4, $\mathrm{Z}=3-\mathrm{NO}_{2}{ }^{\mathrm{h}}$
$\begin{array}{lll}18.06 & 5.88 & 12.18\end{array}$
4, $\mathrm{Z}=\mathrm{H}^{\mathrm{h}}$
$\begin{array}{lll}18.29 & 5.93 \quad 12.36\end{array}$
azide $^{\mathrm{d}}$
6.23
3, $\mathrm{Z}=\mathrm{Me}^{\mathrm{g}}$
$\begin{array}{lll}19.35 & 6.27 & 13.08\end{array}$
$\mathrm{Ph}_{2} \mathrm{P}(\mathrm{O}) \mathrm{CHC}\left(\mathrm{O}^{-}\right) \mathrm{OEt}^{\mathrm{e}}$
$\begin{array}{lll}19.20 & 6.27 & 12.93\end{array}$
$\mathrm{Ph}_{2} \mathrm{P}(\mathrm{O}) \mathrm{CH}^{-} \mathrm{CN}^{\mathrm{e}}$
$\begin{array}{lll}18.69 & 6.30 & 12.39\end{array}$
4, $\mathrm{Z}=4-\mathrm{Me}^{\mathrm{h}}$
$\begin{array}{lll}18.31 & 6.35 & 11.96\end{array}$
5, $\mathrm{Z}=4-\mathrm{NO}_{2}{ }^{\mathrm{i}}$
$\begin{array}{lll}18.5 & 6.45 & 12.05\end{array}$

${ }^{a}$ From Eqn (2) and kinetic data referenced for each nucleophile.

${ }^{\mathrm{b}}$ Calculated from Eqn (7) and kinetic data referenced for each nucleophile.

${ }^{\mathrm{c}} \Delta N=N-N^{\prime \prime \prime}$.

${ }^{\mathrm{d}}$ Reference [7].

${ }^{\mathrm{e}}$ Reference [21].

${ }^{\mathrm{f}}$ Reference [25].

${ }^{\mathrm{g}}$ Reference [20].

${ }^{\mathrm{h}}$ Reference [19].

${ }^{\mathrm{i}}$ Reference [22]. 
TABLE 3. Correlations (Eqn (8)) of second order rate constants for reactions of benzhydrylium ions (1a-1f) with carbanions and amines in DMSO at $20{ }^{\circ} \mathrm{C}$ with $N^{\prime \prime \prime}$ a

$$
\begin{aligned}
& \begin{array}{lllll}
\text { Cation }^{\mathrm{b}} & s_{E} & E^{\prime \prime \prime}+c & \mathrm{r} & \mathrm{n}
\end{array} \\
& \text { (lil) }{ }_{2} \mathrm{CH}^{+}(\mathbf{1 f}) \quad 1.00^{\mathrm{c}} \quad 0.0^{\mathrm{c}} \\
& (\text { jul })_{2} \mathrm{CH}^{+}(\mathbf{1 e}) \quad 0.96 \pm 0.02 \quad 0.62 \pm 0.08 \quad 0.999 \quad 7 \\
& \begin{array}{llll}
0.98 \pm 0.01 & 0.51 \pm 0.03 & 0.999 & 19
\end{array} \\
& \text { (ind) }{ }_{2} \mathrm{CH}^{+} \text {(1d) } 0.95 \pm 0.03 \quad 1.13 \pm 0.13 \quad 0.999 \quad 4 \\
& \begin{array}{llll}
1.00 \pm 0.02 & 0.84 \pm 0.10 & 0.997 & 15
\end{array} \\
& \text { (thq) }{ }_{2} \mathrm{CH}^{+} \text {(1c) } \quad 0.89 \pm 0.05 \quad 1.88 \pm 0.24 \quad 0.997 \quad 4 \\
& 0.99 \pm 0.04 \quad 1.32 \pm 0.19 \quad 0.992 \quad 11 \\
& \text { (pyr) }{ }_{2} \mathrm{CH}^{+} \text {(1b) } 0.91 \pm 0.06 \quad 2.33 \pm 0.290 .998 \quad 3 \\
& \begin{array}{llll}
1.10 \pm 0.07 & 1.46 \pm 0.28 & 0.994 & 5^{\mathrm{d}}
\end{array} \\
& \text { (dma) }{ }_{2} \mathrm{CH}^{+}(\mathbf{1 a}) 0.97^{\mathrm{e}} \quad 2.45^{\mathrm{e}} \quad 2 \\
& 1.10 \pm 0.05 \quad 1.87 \pm 0.16 \quad 0.996 \quad 5^{\mathrm{f}}
\end{aligned}
$$

${ }^{a}$ The first entry for each electrophile refers to kinetic data for reactions of key carbanions in Scheme 3 from References [11,12]; the second entry includes mostly amines (from References [7, 25]) and additional carbanion nucleophiles.

${ }^{\mathrm{b}}$ Structures are given in Scheme 2.

${ }^{\mathrm{c}}$ By definition.

${ }^{\mathrm{d}}$ The nucleophiles are $\mathbf{2 a}, \mathbf{2 b}, \mathbf{2 c},\left(\mathbf{3}, \mathrm{Z}=\mathrm{NO}_{2}\right)$, and ylid $\mathrm{Ph}_{3} \mathrm{PCHCO}_{2} \mathrm{Et}$.

${ }^{\mathrm{e}}$ Errors not known because $\mathrm{n}=2$.

${ }^{\mathrm{f}}$ The nucleophiles are $\mathbf{2 a}, \mathbf{2 b}, \mathrm{CF}_{3} \mathrm{CH}_{2} \mathrm{NH}_{2}, \mathrm{H}_{2} \mathrm{NCH}_{2} \mathrm{CO}_{2} \mathrm{Et}$, and ylid $\mathrm{Ph}_{3} \mathrm{PCHCO}_{2}$ Et. 
TABLE 4. Correlations (Eqn (8)) of second order rate constants for reactions of quinone methides $(\mathbf{1 g}-\mathbf{1 m})$ with carbanions in DMSO at $20{ }^{\circ} \mathrm{C}$ with $N^{\prime \prime \prime}$ a

\begin{tabular}{clccl} 
Quinone $^{\mathrm{b}}$ & \multicolumn{1}{c}{$s_{E}$} & $E^{\prime \prime \prime}+c$ & $\mathrm{r}$ & $\mathrm{n}$ \\
$\mathbf{1 g}$ & $1.00^{\mathrm{c}}$ & $1.08 \pm 0.05$ & & 3 \\
$\mathbf{1 h}$ & $1.25 \pm 0.02$ & $-2.94 \pm 0.13$ & 0.999 & 7 \\
& $1.23 \pm 0.08$ & $-2.76 \pm 0.46$ & 0.982 & $11^{\mathrm{d}}$ \\
$\mathbf{1 i}$ & $1.25 \pm 0.02$ & $-3.82 \pm 0.11$ & 0.999 & 7 \\
& $1.22 \pm 0.08$ & $-3.74 \pm 0.42$ & 0.978 & 14 \\
$\mathbf{1 j}$ & $1.43 \pm 0.01$ & $-6.56 \pm 0.07$ & 0.999 & 7 \\
& $1.34 \pm 0.10$ & $-6.03 \pm 0.57$ & 0.969 & 14 \\
$\mathbf{1 k}$ & $1.41 \pm 0.01$ & $-6.68 \pm 0.05$ & 0.999 & 7 \\
& $1.33 \pm 0.10$ & $-6.17 \pm 0.61$ & 0.965 & 14 \\
$\mathbf{1 1}$ & $1.42 \pm 0.03$ & $-7.52 \pm 0.20$ & 0.999 & 6 \\
& $1.20 \pm 0.15$ & $-6.22 \pm 0.87$ & 0.916 & 15 \\
& $1.28 \pm 0.12$ & $-6.76 \pm 0.72$ & 0.955 & $13^{\mathrm{f}}$ \\
& $1.43 \pm 0.07$ & $-8.00 \pm 0.44$ & 0.995 & 6 \\
& $1.34 \pm 0.14$ & $-7.40 \pm 0.84$ & 0.949 & 12 \\
& $1.45 \pm 0.06$ & $-8.13 \pm 0.36$ & 0.993 & $10^{\mathrm{f}}$
\end{tabular}

${ }^{a}$ First entry for each electrophile refers to kinetic data for reactions of the key carbanions in Scheme 3 from References [11,12]; a second entry includes additional carbanion nucleophiles (Table 2), usually covering a relatively small range of values of $N^{\prime \prime \prime}$. ${ }^{\mathrm{b}}$ Structures are given in Scheme 2.

${ }^{\mathrm{c}}$ Assumed $s_{\mathrm{E}}=1.00$.

${ }^{\mathrm{d}}$ Excluding the data point for ylid $\mathrm{Ph}_{3} \mathrm{PCHCO}_{2} \mathrm{Et}$.

e The rate constant for reaction with $2 \mathrm{~g}$ was assumed to be $69.9 \mathrm{M}^{-1} \mathrm{~s}^{-1}$ (not 699 , shown in Table $2^{[12]}$ ), in accordance with the constant selectivity plot (Figure 2 of Reference [12]). ${ }^{\mathrm{f}}$ After deletion of the data points for $(\mathrm{EtO})_{2} \mathrm{P}(\mathrm{O}) \mathrm{CH}^{-} \mathrm{CN}$ and $(\mathrm{EtO})_{2} \mathrm{P}(\mathrm{O}) \mathrm{CHC}\left(\mathrm{O}^{-}\right) \mathrm{OEt}$. 
Table 5. Values of $N$ and $N^{\prime \prime \prime}$ (Eqn (9)) for additional nucleophiles in DMSO at $20{ }^{\circ} \mathrm{C}$
Nucleophile
$N^{\mathrm{a}} \quad N^{\prime \prime \prime} \mathrm{b} \Delta N^{\mathrm{c}}$
8, $\mathrm{Z}=\mathrm{NO}_{2}{ }^{\mathrm{d}}$
$19.61 \quad 6.2 \quad 13.4$
7, $\mathrm{Z}=\mathrm{NO}_{2}{ }^{\mathrm{d}}$
$19.67(6.5) 13.2$
$9^{\mathrm{e}}$
$19.92 \quad(6.5) \quad 13.4$
$6 \mathbf{a}^{\mathrm{f}}$
$\begin{array}{lll}20.71 & 6.7 & 14.0\end{array}$
$6 c^{f}$
$\begin{array}{lll}20.61 & 6.9 & 13.7\end{array}$
$\mathbf{6 b}^{\mathrm{f}}$
$21.54 \quad 7.2 \quad 14.3$
5, $\mathrm{Z}=4-\mathrm{CN}^{\mathrm{g}}$
$22.6 \quad 7.5 \quad 15.1$
5, $\mathrm{Z}=4-\mathrm{CF}_{3}{ }^{\mathrm{g}}$
$\begin{array}{lll}24.3 & 7.9 & 16.4\end{array}$
7, $\mathrm{Z}=\mathrm{CN}^{\mathrm{d}}$
$\begin{array}{lll}25.11 & 8.3 & 16.8\end{array}$
5, $\mathrm{Z}=3-\mathrm{Cl}^{\mathrm{g}}$
8.4
8, $\mathrm{Z}=\mathrm{CN}^{\mathrm{d}}$
$\begin{array}{lll}25.35 & 8.7 & 16.7\end{array}$
7, $\mathrm{Z}=\mathrm{CF}_{3}^{\mathrm{d}}$
$27.28 \quad 8.9 \quad 18.4$
8, $\mathrm{Z}=\mathrm{H}^{\mathrm{d}}$
$28.95 \quad 10.1 \quad 18.9$

${ }^{a}$ From Eqn (2) and kinetic data in references shown for each nucleophile.

${ }^{\mathrm{b}}$ Based on Eqn (9) and kinetic data in references shown for each nucleophile, except for the 3 values in parentheses which are estimated from correlations for quinone methides (1h, $\mathbf{1 j}$ and $\mathbf{1 k})$.
${ }^{\mathrm{c}} \Delta N=N-N^{\prime \prime \prime}$.
${ }^{\mathrm{d}}$ Reference [23].
${ }^{\mathrm{e}}$ Reference [24].
${ }^{f}$ Reference [19].
${ }^{\mathrm{g}}$ Reference [22]. 
TABLE 6. Correlations (Eqn (8)) of second order rate constants for reactions of neutral electrophiles (10-18) with carbanions in DMSO at $20{ }^{\circ} \mathrm{C}$ with $N^{\prime \prime \prime}$ a

Electrophile $^{\mathrm{b}} \quad s_{E} \quad E^{\prime \prime \prime}+c \quad \mathrm{r} \quad \mathrm{n}^{\mathrm{b}}$

10, $\mathrm{Z}=\mathrm{H}^{\mathrm{c}} \quad 1.00^{\mathrm{d}} \quad 0.4 \quad 3$

10, $\mathrm{Z}=\mathrm{OMe}^{\mathrm{c}} \quad 1.38 \pm 0.05 \quad-2.88 \pm 0.34 \quad 0.999 \quad 3$

$1.18 \pm 0.14 \quad-1.64 \pm 0.88 \quad 0.987 \quad 4$

10, $\mathrm{Z}=\mathrm{NMe}_{2}{ }^{\mathrm{c}} \quad 1.32 \pm 0.02 \quad-4.23 \pm 0.14 \quad 0.999 \quad 3$

$1.31 \pm 0.01 \quad-4.17 \pm 0.08 \quad 0.999 \quad 4$

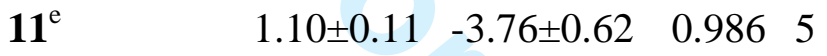

$1.16 \pm 0.10 \quad-4.21 \pm 0.59 \quad 0.978 \quad 8$

$0.97 \pm 0.08 \quad-3.19 \pm 0.51 \quad 0.962 \quad 15$

$12, \mathrm{Z}=\mathrm{NMe}_{2}{ }^{\mathrm{e}} \quad 1.03 \pm 0.10 \quad-2.54 \pm 0.56 \quad 0.987 \quad 5$

$\begin{array}{llll}1.07 \pm 0.12 & -2.89 \pm 0.73 & 0.962 & 8\end{array}$

$0.92 \pm 0.08 \quad-2.11 \pm 0.55 \quad 0.955 \quad 14$

12, $\mathrm{Z}=\mathrm{OMe}^{\mathrm{e}} \quad 1.0^{\mathrm{d}} \quad-0.8 \quad 3$

$\left(\begin{array}{llll}0.64 \pm 0.11 & 1.13 \pm 0.66 & 0.955 \quad 5\end{array}\right)$

$\begin{array}{lll}1.0^{\mathrm{f}, \mathrm{g}} & -0.8 & 8\end{array}$

12, $\mathrm{Z}=\mathrm{H}^{\mathrm{e}} \quad 1.0^{\mathrm{d}, \mathrm{h}} \quad-0.1 \quad 3$

13, $\mathrm{X}=\mathrm{O}^{\mathrm{i}} \quad 1.09 \pm 0.16 \quad-3.05 \pm 0.96 \quad 0.9596$

$1.22 \pm 0.09-3.97 \pm 0.54 \quad 0.976 \quad 11$

$\begin{array}{llll}0.89 \pm 0.09 & -2.06 \pm 0.57 & 0.944 & 14\end{array}$

14, $Z=\mathrm{NMe}_{2}{ }^{\mathrm{i}} \quad 0.98 \pm 0.15 \quad-1.67 \pm 0.88 \quad 0.957 \quad 6$

$1.18 \pm 0.16 \quad-2.95 \pm 0.94 \quad 0.948 \quad 8$

$0.82 \pm 0.11 \quad-0.93 \pm 0.71 \quad 0.908 \quad 13$

14, Z=OMe $\quad 1.00 \pm 0.07 \quad-0.20 \pm 0.38 \quad 0.9897$

$\begin{array}{llll}0.99 \pm 0.07 & -0.20 \pm 0.42 & 0.983 \quad 8\end{array}$

$0.84 \pm 0.18 \quad 0.47 \pm 1.04 \quad 0.857 \quad 10^{\mathrm{j}}$

13, $X=S^{\mathrm{i}} \quad 0.90 \pm 0.14 \quad-0.70 \pm 0.82 \quad 0.957 \quad 6$

$\begin{array}{lllll}15^{\mathrm{i}} & 0.99 \pm 0.09 & -0.49 \pm 0.48 & 0.985 & 6\end{array}$ 


$$
\begin{array}{lllll}
\mathbf{1 6}, \mathrm{Z}=\mathrm{H}^{\mathrm{k}} & 1.0^{\mathrm{d}} & 0.7 & & 2 \\
\mathbf{1 6}, \mathrm{Z}=\mathrm{OMe}^{\mathrm{k}} & 0.93 \pm 0.08 & 0.27 \pm 0.46 & 0.981 & 7 \\
& 0.92 \pm 0.09 & 0.27 \pm 0.49 & 0.975 & 8 \\
\mathbf{1 6}, \mathrm{Z}=\mathrm{NMe}_{2}{ }^{\mathrm{k}} & 0.99 \pm 0.20 & -1.77 \pm 1.18 & 0.928 & 6 \\
& 1.01 \pm 0.21 & -1.93 \pm 1.23 & 0.909 & 7 \\
\mathbf{1 7}^{\mathrm{k}} & 1.16 \pm 0.21 & -3.59 \pm 1.27 & 0.939 & 6 \\
& 1.06 \pm 0.18 & -3.08 \pm 1.09 & 0.925 & 8 \\
& 0.72 \pm 0.12 & -1.11 \pm 0.77 & 0.901 & 11^{1} \\
\mathbf{1 8}, \mathrm{Z}=4-\mathrm{NO}_{2}{ }^{\mathrm{m}} & 1.54 \pm 0.13 & -8.52 \pm 0.85 & 0.996 & 3 \\
& 1.40 \pm 0.26 & -7.74 \pm 1.73 & 0.951 & 5 \\
& 1.36 \pm 0.10 & -7.47 \pm 0.72 & 0.983 & 8 \\
\mathbf{1 8}, \mathrm{Z}=4-\mathrm{CN}^{\mathrm{m}} & 1.57 \pm 0.42 & -9.1 \pm 2.8 & 0.934 & 4 \\
& 1.37 \pm 0.13 & -7.81 \pm 0.93 & 0.979 & 7^{\mathrm{n}} \\
\mathbf{1 8}, \mathrm{Z}=3-\mathrm{Cl}^{\mathrm{m}} & 1.56 \pm 0.38 & -9.6 \pm 2.5 & 0.946 & 4 \\
& 1.43 \pm 0.13 & -8.83 \pm 0.94 & 0.984 & 6^{\mathrm{n}}
\end{array}
$$

${ }^{a}$ Italic entries refer to the same data set of nucleophiles (Tables 2 and 5), as that used to obtain values of $E$ from the MPC3 optimisations fitting Eqn (2); kinetic data are from the references shown for each electrophile; if an earlier entry is shown, it refers to kinetic data for reactions of the key carbanions (Scheme 3); a later entry refers to the incorporation into Eqn (8) of subsequently-published data from References [22-24].

${ }^{\mathrm{b}}$ Structures are given in Scheme 5; values of $E$ are in the References shown below.

${ }^{\mathrm{c}}$ Reference [13].

d Assumed.

${ }^{\mathrm{e}}$ Reference [14].

${ }^{\mathrm{f}}$ Assuming $s_{\mathrm{E}}=1.0$ gives more plausible results than Eqn (8) for nucleophiles 7, 8, Z = $\mathrm{NO}_{2}$ and 9.

${ }^{\mathrm{g}} \mathbf{5}, \mathrm{Z}=\mathrm{NO}_{2}$ is predicted to react 20 -fold faster than observed.

${ }^{\mathrm{h}}$ This equation also fits data for $8, \mathrm{Z}=\mathrm{NO}_{2}$.

${ }^{\mathrm{i}}$ Reference [15].

${ }^{\mathrm{j}} \mathbf{5}, \mathrm{Z}=\mathrm{NO}_{2}$ is calculated to react 13-fold faster than observed.

${ }^{\mathrm{k}}$ Reference [16].

${ }^{1}$ The additional nucleophiles are $5, \mathrm{Z}=3-\mathrm{Cl}, 4-\mathrm{CF}_{3}$ and $4-\mathrm{CN}$.

${ }^{\mathrm{m}}$ Reference [17].

${ }^{\mathrm{n}}$ Only two key nucleophiles (Scheme 3); additional kinetic data from Reference [23]. 
TABLE 7. Correlations (Eqn (8)) of second order rate constants for reactions of additional quinone methide (QM) electrophiles (19) with key carbanions (Scheme 3) in DMSO at $20{ }^{\circ} \mathrm{C}$ with $N^{\prime \prime \prime}$

$\begin{array}{ccccc}\mathrm{QM}^{\mathrm{a}} & s_{E} & E^{\prime \prime \prime}+c & \mathrm{r} & \mathrm{n} \\ & & & & \\ \text { 19a } & 1.50 \pm 0.07 & -6.49 \pm 0.42 & 0.997 & 5 \\ \text { 19b } & 1.51 \pm 0.09 & -6.15 \pm 0.54 & 0.995 & 5 \\ \text { 19c } & 1.45 \pm 0.08 & -5.66 \pm 0.47 & 0.994 & 6 \\ \text { 19d } & 1.20 \pm 0.05 & -2.42 \pm 0.24 & 0.998 & 5 \\ \text { 19e } & 1.36 \pm 0.04 & -6.55 \pm 0.23 & 0.999 & 4^{\mathrm{b}}\end{array}$

${ }^{a}$ The quinone methide electrophiles (19, Scheme 6) are structural variations on those given in Scheme 2, but the kinetic data were obtained ${ }^{[18]}$ years after MPC1; ${ }^{[11]}$ values of $E$ are in Scheme 6

${ }^{\mathrm{b}}$ Data includes carbanion $\mathbf{6 b}$. 
Table 8. Comparisons of $s_{\mathrm{N}} N$ and $N^{\prime}$ with $\mathrm{p} K_{\mathrm{a}}$ values for arylacetonitriles in DMSO

Carbanion $^{\mathrm{a}} \quad \mathrm{p} K_{\mathrm{a}}^{\mathrm{b}} \quad s_{\mathrm{N}} N^{\mathrm{c}} \quad N^{\prime \prime \prime}$

$\begin{array}{llll}7, \mathrm{Z}=\mathrm{NO}_{2} & 12.3 & 13.38 & 6.5\end{array}$

$\begin{array}{llll}7, \mathrm{Z}=\mathrm{CN} & 16.0 & 13.56 & 8.3\end{array}$

$7, \mathrm{Z}=\mathrm{CF}_{3} \quad 18.1 \quad 13.64 \quad 8.9$

$\mathbf{8}, \mathrm{Z}=\mathrm{H} \quad 23.0 \quad 16.79 \quad 10.1$

${ }^{\text {a }}$ Structures are in Scheme 4.

${ }^{\mathrm{b}}$ Refers to the conjugate acid; data at $25^{\circ} \mathrm{C}$ from References [31,32].

${ }^{\mathrm{c}}$ From Eqn (2), $s_{\mathrm{N}} N=$ hypothetical $\log k$ estimated for electrophile 1n $(E=0.0)$ in DMSO at $20{ }^{\circ} \mathrm{C}$; data from Reference [23].

${ }^{\mathrm{d}}$ From Table 5. 
Table 9. Comparisons of $s_{\mathrm{N}}$ and $N$ (Eqn 2) calculated from log $k$ vs. $E$ plots (first entry) with values from the multi-parameter correlation (second entry) ${ }^{a}$

Nucleophile $^{\mathrm{b}} \quad s_{\mathrm{N}} \quad N$

2a (6) $\quad 0.806 \pm 0.033 \quad 0.856 \quad 14.24 \quad 13.91$

2b (6) $\quad 0.787 \pm 0.036 \quad 0.767 \quad 16.12 \quad 16.27$

2c (5) $\quad 0.755 \pm 0.026 \quad 0.729 \quad 17.30 \quad 17.64$

2d (4) $\quad 0.623 \pm 0.027 \quad 0.688 \quad 19.81 \quad 18.82$

${ }^{a}$ Kinetic data and parameters from the multi-parameter correlation (MPC2) are from Reference [11].

${ }^{\mathrm{b}}$ The nucleophiles are key carbanions (Scheme 3 ) and the number of data points for the $\log k$ vs. $E$ plots is also shown. 
Graphical Table of Contents

\section{Nucleophilicity parameters for strong nucleophiles in dimethyl sulfoxide. A direct alternative to the $s(E+N)$ equation}

T. William Bentley

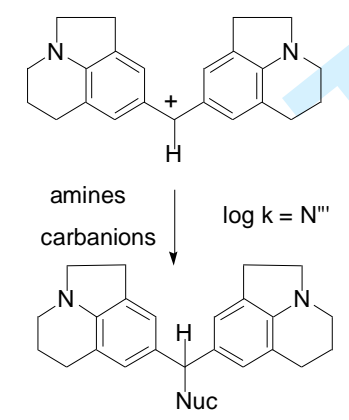

A nucleophilicity scale $\left(N^{\prime \prime \prime}\right)$ is defined for 34 strong nucleophiles (e.g. carbanions and amines) and is linked to two previously-defined nucleophilicity scales ( $N^{\prime}$ and $N^{\prime \prime}$ ) including 96 nucleophiles. The unified $N^{\prime \prime}$ scale spans $10^{22}$ in rate constant, whereas the floating $N$ scale spans 32 orders of magnitude. 